Commentary

\title{
Meningitis during COVID -19 pandemic in the Democratic Republic of Congo: A call for concern
}

\begin{abstract}
A B S T R A C T
Meningitis is a severe infection and a major public health challenge. The meningitis outbreak which had resurfaced amid the coronavirus disease 2019 (COVID-19) pandemic in the Democratic Republic of Congo (DRC) has been further stressing the health care systems that are already overburdened with detecting, preventing, and treating the current coronavirus disease. The recent meningitis outbreak in the DRC has resulted in a high case fatality ratio of $50 \%$ - an extremely worrying concern. Robust strategies are hence needed to curb the spread of the disease amid the COVID-19 pandemic, to prevent further adverse health outcomes and to mitigate the compounding burden on the country's healthcare systems. Several measures such as vaccination campaigns, adherence to sanitation and hygiene, improved surveillance and diagnostic capabilities could help prevent future epidemics in the country.
\end{abstract}

\section{Commentary}

Amid the coronavirus disease 2019 (COVID-19) pandemic, a meningitis outbreak has re-emerged in the Democratic Republic of Congo (DRC). Meningitis is a serious infection of the meninges, which are the films covering the brain and spinal line ${ }^{1 .}$ It is a deadly disease and remains a major public health challenge. More than 1.2 million cases of bacterial meningitis occur worldwide annually, with the highest prevalence in sub-Saharan African. ${ }^{2}$ This hyper-endemic region extends from Senegal to Ethiopia, Angola, Burundi, DRC and Zambia. ${ }^{2}$ The infection can be caused by a plethora of pathogens which include fungi, bacteria, or viruses, among which the most noteworthy worldwide threat being bacterial meningitis. ${ }^{1}$ It is transmitted among people through droplets of respiratory or throat secretions from infected people. ${ }^{1}$ Close and prolonged contact or living in close quarters with an infected person facilitates the spread of the disease. ${ }^{1}$ Environmental and socio-economic conditions are some of the main drivers of meningitis in sub-Saharan Africa. $^{3,4}$

Meningitis outbreaks have occurred in several Provinces of the DRC in the past. ${ }^{5}$ The DRC has reported more than 118,000 cases of meningitis between the period of 2000-2018 with a mortality rate of $11.5 \%{ }^{6}$ In 2009, the Province Tshopo experienced an outbreak of meningitis in the city of Kisangani which infected 214 people and caused 15 deaths with a case fatality ratio of $8 \% .{ }^{5}$ However, since 2009 , only passive surveillance was implemented in the province as part of the integrated disease surveillance. On September 7, 2021, the National Minister of Public Health announced meningitis outbreak in Tshopo region in the DRC. ${ }^{7}$ The recent outbreak of meningitis in Tshopo with 267 cases, 129 related deaths and a high case fatality ratio of $50 \%$ is a worrying concern. ${ }^{5}$ Other African countries have also experienced meningitis outbreak this year but with mortality rate below $8 \% .{ }^{6}$ With the high case fatality ratio of meningitis in the DRC, meeting the Global Task Force on Meningitis Control's 2030 target of reducing meningitis infection by $50 \%$ and deaths by $70 \%{ }^{5}$ will require speeding up the fight against meningitis in DRC, even during the pandemic.

Currently there are three types of vaccines available for the prevention of meningitis: Polysaccharide-protein conjugate vaccines, Protein based vaccines against serogroup B and Polysaccharide vaccines. ${ }^{8}$ Although a massive meningitis campaign was organised in 2016 in the Tshopo Province where over 1.6 million individuals between 1 and 29 years were vaccinated. ${ }^{5}$ However, the vaccination only targeted meningitis A, the current outbreak has been driven by meningitis $\mathrm{W}{ }^{6}$ Currently, preparations are being made for a new vaccination campaign, to target the new strain. However, a swift and coordinated response is required.

Efforts are underway to contain the outbreak. A crisis response committee has been set up in Banalia which is the site of the outbreak, and in Kisangani, the capital of Tshopo. The World Health Organization (WHO) has supplied medicines and deployed experts to deal with the outbreak. More than 100 people are already receiving treatment at home and in health facilities. ${ }^{5}$ Moreover, mobile clinics have also been set up and two reference hospitals are now dedicated to aid in management of patients diagnosed with meningitis. ${ }^{6}$

Apart from meningitis and COVID-19 the country has experienced several outbreaks, which include the second-deadliest Ebola plague that just ended and the world's worst measles flare-up. ${ }^{9-11}$ The fragile health system of DRC is already under great burden due to measles, malaria, COVID-19, cholera, monkeypox, pneumonic plague, poliomyelitis, yellow fever and typhoid fever amidst other humanitarian crises.11,12 In addition, the state of healthcare in the DRC is poor as a result of shortage of qualified healthcare staff and grossly underfunded healthcare sector. The current health expenditure is only a mere $3.3 \%$ of the total Gross Domestic Product (GDP) of the country. ${ }^{13}$ Fragmentation and poor coordination within the health sector remain prevalent which has contributed to inefficiencies in the health system. Timely and effective interventions are needed to prevent a collapse of the health system of the DRC which can occur if the meningitis outbreak spreads more rapidly and widely. 
Several factors are driving the meningitis epidemic in the country, and inadequate diagnostic capacity in affected areas is one of them; thereby delaying the ability to detect the causal agent and hence limiting a target response to the situation. ${ }^{12}$ Moreover, access to the affected areas is proving to be extremely difficult due to poor roads networks and challenging terrains. ${ }^{12}$ Information and data sharing is also strained because of inadequate and unstable telecommunication network coverage making it arduous to conduct accurate epidemiological trend analysis. ${ }^{12}$ Rumours of witchcraft have contributed to the difficulty in the containment of the outbreak as those affected are wary of medical treatments, believing them to be linked to witchcraft. ${ }^{6}$ In addition, the country's weak disease surveillance systems, poor hygienic conditions, poor emergency preparedness and the ongoing humanitarian crises are also causes of concern. In addition, several other challenges persist.

Adding to the woes is the monumental challenges in timely and accurate diagnosis of meningitis amidst the COVID-19 pandemic given the resource limited settings in the DRC and as a result of overlapping clinical presentations especially in cases of co-infection between the two diseases. ${ }^{14,15}$ The symptomatology of COVID-19 is diverse and pervasive which range from asymptomatic infection, mild respiratory symptoms and even severe respiratory failure leading to death. Fever, fatigue, headache, anosmia, hyposmia and mild respiratory symptoms like dry cough are few of the common presenting symptoms associated with COVID-19. However, patients may also develop neurological manifestations such as meningitis during the course of the illness. ${ }^{14,15}$ It is therefore important to mobilize resources to help discern the true etiological agent causing meningitis amidst all the cases of the current outbreak. Treatment of bacterial meningitis involves antibiotics such as ampicillin and ceftriaxone which, if given to close contacts of an infected person can help reduce the risk of transmission. ${ }^{1}$ Moreover, polysaccharide, conjugate, and N. meningitidis B vaccines are available which can most definitely aid in preventing future outbreaks and curbing the spread of the disease. ${ }^{1}$

\section{Recommendations and conclusion}

Given the gravity of the meningitis outbreak in the DRC, amidst the pandemic of COVID-19, it is imperative that the authorities in the region take immediate action to mitigate further progression of an already unruly situation. ${ }^{16}$ The meningitis belt, from Senegal to Ethiopia, is particularly vulnerable to the disease. WHO and the international communities should constantly monitor the region to limit the spread, backed by strong laboratory-based systems. ${ }^{5}$

Prevention, effective treatment, and epidemiological surveillance are some of the vital strategies in containing any outbreak. Both meningitis and COVID-19 being preventable diseases, the stakeholders should focus primarily on equitable distribution of vaccines, increasing the coverage in all the districts, and prioritizing 'catch-up' vaccines particularly in children. The healthcare workers should organize community outreach programs to create awareness regarding health and hygiene among the local population.

To address the rumours of witchcraft that have contributed to the difficulty in the containment of the meningitis outbreak, the government should increase communication via radios, newspapers and media as well as involving community, traditional and religious leaders. The inclusion of traditional and spiritual leaders and influential community leaders drawn from affected communities is likely to address the rumours of witch craft and improve understanding and adherence to preventive measures. Since it is known that many people in West African communities often look to traditional and religious leaders for advice in times of health emergencies ${ }^{17,18}$; So, the engagement of traditional and religious leaders and influential community leaders in risk communication should be prioritized during health emergencies.

The policymakers and all relevant stakeholders must take steps to strengthen and increase the country's capacity to identify, manage and create resources, that would be required to effectively control any future outbreak. $^{5}$

\section{Author contributions}

MYE conceived the concept of this letter and OCO prepared the outlines of the study. OCO, SR, SAG, PM, UU, ZI and MYE were responsible for drafts of the manuscript. OCO and SR edited the second draft and improved the manuscript. MYE, OCO and FNB made the critical review of the manuscript. All authors read and approved the final manuscript.

\section{Ethics statement}

Not applicable.

\section{Funding}

No external funding was used in this study.

\section{Availability of data and materials}

Not applicable.

\section{Declaration of competing interest}

No potential conflict of interest was reported by the authors.

\section{Acknowledgements}

Not applicable.

\section{Abbreviations}

WHO World Health Organization

COVID-19 Coronavirusdisease 2019

DRC Democratic Republic of Congo

CFR Case Fatality Ratio

\section{References}

1. Meningitis [Internet]. [cited 2021 Dec 20]. Available from: https://www.who.int/w esternpacific/health-topics/meningitis.

2. Meningitis [Internet] $C D C ; 2021$ [cited 2021 Dec 20]. Available from: https://www, cdc.gov/meningitis/index.html.

3. The environmental drivers of bacterial meningitis epidemics in the Democratic Republic of Congo, Central Africa [Internet]. [cited 2021 Dec 20]. Available from: https://journals.plos.org/plosntds/article?id=10.1371/journal.pntd.0008634.

4. Agier L, Deroubaix A, Martiny N, Yaka P, Djibo A, Broutin H. Seasonality of meningitis in Africa and climate forcing: aerosols stand out. J R Soc Interface. 2013 Feb 6; 10(79), 20120814.

5. Democratic Republic of the Congo Declares Meningitis Outbreak in North-Eastern Province [Internet]. WHO | Regional Office for Africa. [cited 2021 Dec 20]. Available from: https://www. afro.who.int/news/democratic-republic-congo-declaresmeningitis-outbreak-north-eastern-province- 0 .

6. Fears of witchcraft delay meningitis declaration in DRC | Devex [Internet]. [cited 2021 Dec 20]. Available from: https://www.devex.com/news/fears-of-witchcraft-d elay-meningitis-declaration-in-drc-101573.

7. Congo DR. Meningitis outbreak [Internet] ReliefWeb; Sep 2021 [cited 2021 Dec 20]. Available from: https://reliefweb.int/disaster/ep-2021-000138-cod.

8. Meningitis [Internet]. [cited 2021 Dec 20]. Available from: https://www.who.int/ news-room/fact-sheets/detail/meningitis.

9. Khan FMA, Hasan MM, Kazmi Z, et al. Ebola and COVID-19 in Democratic Republic of Congo: grappling with two plagues at once. Trop Med Health. 2021 Aug 24;49(1): 67.

10. Mohan A, Temitope RA, Cavdaroğlu S, et al. Measles returns to the Democratic Republic of Congo: a new predicament amid the COVID-19 crisis. J Med Virol. 2021 Oct; 93(10):5691-5693.

11. On life support | UNICEF-en [Internet]. [cited 2021 Dec 20]. Available from: https ://www.unicef.org/drcongo/en/reports/life-support.

12. OEW36-300805092021.pdf [Internet]. [cited 2021 Dec 20]. Available from: htt ps://apps.who.int/iris/bitstream/handle/10665/345001/OEW36-300805092021. pdf.

13. Current health expenditure (\% of GDP) | Data [Internet]. [cited 2021 Dec 20]. Available from: https://data.worldbank.org/indicator/SH.XPD.CHEX.GD.ZS. 
14. Naz S, Hanif M, Haider MA, Ali MJ, Ahmed MU, Saleem S. Meningitis as an initial presentation of COVID-19: a case report. Front Public Health. 2020;8:474.

15. Yousefi K, Poorbarat S, Abasi Z, Rahimi S, Khakshour A. Viral meningitis associated with COVID-19 in a 9-year-old child: a case report. Pediatr Infect Dis J. 2021 Feb 1;40 (2):e87-98.

16. Immunization agenda 2030 [Internet]. [cited 2021 Dec 20]. Available from: htt ps://www.who.int/teams/immunization-vaccines-and-biologicals/strategies/i a2030.

17. Alexander KA, Sanderson CE, Marathe M, et al. What factors might have led to the emergence of Ebola in West Africa? PLoS Neglected Trop Dis. 2015 Jun 4;9(6), e0003652.

18. Manguvo A, Mafuvadze B. The impact of traditional and religious practices on the spread of Ebola in West Africa: time for a strategic shift. Pan Afr Med J. 2015 Oct 10; 22(Suppl 1):9.

Osaretin Christabel Okonji School of Pharmacy, University of the Western Cape, Cape Town, South Africa

Sudhan Rackimuthu Father Muller Medical College, Mangalore, Karnataka, India

Shazil Ahmed Gangat Dow University of Health Sciences, Karachi, Pakistan
Parvathy Mohanan

Department of General Medicine, Medical University Sofia, Sofia, Bulgaria

Utkarsha Uday West Bengal University of Health Sciences DD-36, Salt Lake, Sector-1, Kolkata, 700064 India

Zamina Islam Dow University of Health Sciences, Karachi, Pakistan

Mohammad Yasir Essar Kabul University of Medical Sciences, Kabul, Afghanistan

Fidèle Nyimi Bushabu Service of Oral and Maxillofacial Surgery, Department of Dental Medicine, Faculty of Medicine, University of Kinshasa, Kinshasa, Congo

* Corresponding author. E-mail address: Yasir.essar@gmail.com (M.Y. Essar). 